$\underline{\text { Original Articles }}$

\title{
A study of antibiotic usage in acute respiratory infections in children
}

\author{
M N Lucas ${ }^{1}$, U A Liyanage ${ }^{1}$, L K U I Lokukankanamage ${ }^{1}$ \\ Sri Lankan Journal of Child Health, 2001; 30: 5-7
}

(Key words: antibiotic usage, acute respiratory infection, children)

\begin{abstract}
Objective To study antibiotic usage pattern in acute respiratory infections (ARI) in children.

Design A descriptive cross-sectional study.

Setting Five medical wards of the Lady Ridgeway Hospital, Colombo.
\end{abstract}

Patients One hundred children between 2 months and 12 years with ARI.

Method Data was collected using an interviewer administered questionnaire. Information recorded in the Bed Head Ticket was also used.

Results Thirty nine children with ARI were given antibiotics prior to hospital admission. 71 children with ARI were given antibiotics after hospital admission. Only 24 children had clinical, laboratory or radiological evidence of bacterial infection.

Conclusion $47 \%$ children with possibly non-bacterial ARI had been unnecessarily prescribed antibiotics in the ward setting.

\section{Introduction}

Acute respiratory infections (ARI) are a major cause of morbidity and mortality world-wide ${ }^{1}$. Four out of 15 million deaths that occur in the under 5 year olds are due to ARI which is one of the major causes of death in children in developing countries ${ }^{2}$. Most children have four to six episodes of ARI each year and they make up a large proportion of patients seen by health workers. This applies even more to urban than rural areas ${ }^{3}$.

Of the ARI in children, bacterial pneumonia has been identified as a major cause of death which can be prevented by early diagnosis and treatment with appropriate antibiotics ${ }^{4}$. However, as most of the

\footnotetext{
${ }^{1}$ Medical Student, Faculty of Medicine, Colombo.
}

ARI are viral in origin, antibiotics need not be prescribed routinely ${ }^{5}$. Nevertheless, it is well known that ARI is one of the illnesses most frequently associated with abuse of antibiotics ${ }^{6}$. Presumptive antibiotic usage for ARI remains a common practice in paediatrics despite evidence that no therapeutic benefit is derived for the patient and sometimes harmful consequences result ${ }^{5}$.

\section{Objective}

To study the antibiotic usage pattern in acute respiratory infections (ARI) in children.

\section{Design}

A descriptive cross sectional study.

\section{Method}

The study population consisted of children between 2 months and 12 years of age admitted to 5 paediatric medical wards of the Lady Ridgeway Hospital, Colombo with symptoms of respiratory tract infection of less than 10 days duration. The data was collected over a period of two weeks using an interviewer administered questionnaire together with information recorded in the Bed Head Ticket.

Patients presenting with one or more of the following symptoms were taken as having $\mathrm{ARI}^{3}$.

- Cough

- Shortness of breath

- Sore throat

- Runny nose

- Purulent ear discharge

- Earache

Patients presenting with any symptoms other than those mentioned above with the exception of fever and wheezing were excluded from the study.

The presence of one or more of the following signs was taken as clinical evidence of bacterial ARI. 
- Bronchial breathing

- Dullness on percussion of the chest

- Reduced movement on the affected side of the chest.

- Stridor and drooling of saliva in a calm child.

- Pus draining from the ear drum.

- Red immobile ear drum.

- Exudates on throat.

One or more of the following radiological or laboratory findings were taken as positive evidence of bacterial ARI.

- Consolidation, lung abscess or ground glass appearance on chest $\mathrm{x}$-ray.

- Opacity of a paranasal sinus on sinus x-ray.

- Opacity in the retropharyngeal space in lateral neck x-ray.

- Neutrophil leucocytosis

- Cultures from sputum or nasopharyngeal aspirate positive for a bacterial infection.

\section{Results}

A total of 100 children with ARI were studied. There were 53 boys and 47 girls. The age distribution is shown in Table 1.

Table 1

Age Distribution

\begin{tabular}{|c|c|}
\hline Age (months) & No. of children \\
\hline $02-24$ & 66 \\
\hline $25-48$ & 17 \\
\hline $49-72$ & 07 \\
\hline $73-96$ & 05 \\
\hline $97-120$ & 03 \\
\hline $121-144$ & 02 \\
\hline
\end{tabular}

The distribution of presenting complaints in children with ARI is shown in Table 2.

Table 2

Distribution of presenting complaints in children with ARI

\begin{tabular}{|c|c|}
\hline Presenting complaint & No. of children \\
\hline Cough & 95 \\
\hline Shortness of breath & 64 \\
\hline Runny nose & 34 \\
\hline Sore throat & 01 \\
\hline Ear ache & 01 \\
\hline Ear discharge & 01 \\
\hline
\end{tabular}

The distribution of physical signs found at clinical examination in children with ARI is shown in Table 3.

Table 3

Physical signs in children with ARI

\begin{tabular}{|c|c|}
\hline Physical sign & No. of children \\
\hline Crepitations/Rhonchi & 64 \\
\hline Reduced air entry & 08 \\
\hline Bronchial breathing & 06 \\
\hline Reduced chest movement & 04 \\
\hline Stridor & 02 \\
\hline Chest dull on percussion & 01 \\
\hline Exudate in throat & 01 \\
\hline Pus from ear drum & 01 \\
\hline
\end{tabular}

Chest x-rays were done in 29 children with ARI and white cell counts in 28 children. Sinus x-rays, lateral $\mathrm{x}$-rays of neck, culture of sputum or nasopharyngeal aspirates were not done in any of the children. No investigations whatsoever had been done in 53 children.

Antibiotics had been given prior to hospital admission in 39 children. After admission to hospital antibiotics had been prescribed in 71 children. However, evidence of bacterial infection was found in only 24 children (Table 4)

Table 4

Evidence of bacterial infection

\begin{tabular}{|c|c|}
\hline Evidence & No. of children \\
\hline Lab signs only & 09 \\
\hline Clinical signs only & 04 \\
\hline Clinical, x ray \& lab signs & 04 \\
\hline Clinical \& lab signs & 03 \\
\hline Clinical \& x ray signs & 02 \\
\hline X ray signs only & 01 \\
\hline X ray \& lab signs & 01 \\
\hline Total & 24 \\
\hline
\end{tabular}

The 3 most commonly used antibiotics in ARI in our study were amoxycillin (31\%), erythromycin (26\%) and cloxacillin $(17 \%)$.

\section{Discussion}

There was a slight male preponderance in the children with ARI. 83\% children with ARI were in the under 5 year age group. Cough, runny nose and shortness of breath, singly or in combination were present in all 100 children with ARI. The commonest physical signs noted in our study were crepitations and/or rhonchi, found in $64 \%$ of children with ARI. A Sri Lankan study on identification of 
bacterial ARI of childhood concluded that $56.5 \%$ children with ARI had bacterial infections ${ }^{7}$. On the other hand, an American study on outcomes after judicious antibiotic use for ARI concluded that $77 \%$ children with ARI did not have a presumed or proven bacterial infections ${ }^{5}$. In our study $76 \%$ children with ARI did not have evidence of bacterial infection. Whilst only $24 \%$ of the children with ARI in our study had evidence of bacterial infection, $71 \%$ had been given antibiotics. Thus, in our study, $47 \%$ of the children with ARI were given antibiotics unnecessarily. It is recommended that antibiotic usage in ARI in childhood should be confined to those who show clinical, laboratory or radiological evidence of bacterial infection.

\section{Acknowledgements}

We thank the Consultant Paediatricians of the Lady Ridgeway Hospital for allowing us access to children in their wards for this study. We also thank Dr Nalika Gunawardena of the Department of Community Medicine for her invaluable help.

\section{References}

1. Bulla A, Hitze K 1. Acute respiratory infections: A review. Bulletin of the World Health Organization. 1978; 56: 481-97.
2. World Health Organization. Acute respiratory infections in children: case management in small hospitals in developing countries. A manual for doctors and other senior health workers. WHO/ARI/90. 5; pp 57-61.

3. World Health Organization. Management of the young child with an acute respiratory infection. Programme for control of acute respiratory infections, 1991.

4. Grant J P. The state of the world's children 1 990. Oxford: United Nations Children's Fund and Oxford University Press 1990; p 12.

5. Pichichero ME, Green JL, Francis AB, Marsocci SM, Murphy ML. Outcomes after judicious antibiotic use for respiratory tract infections seen in a private practice. Pediatrics $2000 ; 105$ : $753-$ 60.

6. Kumar V. Standard Case Management: A strategy for ensuring prompt recognition and treatment of pneumonia. ARI News Issue no. 31, April-July 1995.

7. Perera A, Wickremasinghe S, Perera BJC, Somaratne P. Reliable and easy identification of bacterial acute respiratory infections of childhood. Ceylon Medical Journal 1998; 43: 201-5. 